\title{
Pelatihan Media Pembelajaran Lectora Inspire Model NBT-Plus pada Guru SMK di Kota Surakarta
}

\author{
Wiedy Murtini, Hery Sawiji, Tri Murwaningsih, Nur Rahmi Akbarini \\ Pendidikan Administrasi Perkantoran, Fakultas Keguruan dan IImu Pendidikan, Universitas Sebelas Maret, \\ Surakarta, Indonesia
}

Submitted: 04 September 2019; Revised: 20 September 2020; Accepted: 13 November 2020

Kata Kunci:
Media
pembelajaran
Lectora inspire
Kemampuan
guru

Keywords: Learning media Lectora inspire Teachers' skill

\begin{abstract}
Abstrak Di era sekarang ini, guru dituntut untuk selalu mengikuti perkembangan saat ini. Keterampilan dalam menggunakan media pembelajaran berbasis teknologi sangat diperlukan bagi guru. Mempertimbangkan analisis kebutuhan, maka dilakukan kegiatan pengabdian kepada masyarakat berupa pelatihan bagi guru SMK tentang otomasi dan tata kelola perkantoran di Kota Surakarta. Tujuan pengabdian adalah untuk menambah pengetahuan guru dalam menggunakan media pembelajaran. Metode yang digunakan dalam kegiatan pengabdian masyarakat ini merupakan rangkaian kegiatan yang meliputi tahapan persiapan, pelatihan, dan pemantauan. Tahap persiapan dilakukan melalui koordinasi tim pengabdian dan mitra, pelatihan dilakukan sepanjang hari dengan memberikan pemahaman tentang media pembelajaran di Lectora Inspire, dan tahap pemantauan dilakukan melalui WhatsApp group yang berfungsi untuk memantau pekerjaan dan memberi ruang kepada peserta untuk pembekalan informal. Output dari kegiatan pelatihan ini adalah peningkatan keterampilan guru dalam menggunakan media pembelajaran. Secara umum peserta diklat mengikuti kegiatan dengan antusias dan manfaat pelatihan ini terlihat dari $95 \%$ peserta yang mengatakan bahwa materi diklat relevan dengan kebutuhan peserta.
\end{abstract}

Abstract' In this era, the teacher is required to keep up with current developments. Skills in using technology-based learning media is very desirable for teachers. Considering the need analysis, a community service activity was conducted in the form of training for vocational high school teachers in office automation and governance in Surakarta City. The objective of service was to increase the teachers' knowledge in using learning media. The methods employed in this community service activity was a series of activities including preparation, training, and monitoring stages. The preparation stage was conducted through coordination of service team and partner, training was conducted all day by giving understanding on Lectora Inspire learning media, and monitoring stage was conducted through WhatsApp group functioning to monitor the work and to give the participants the space for informal debriefing. The output of this training activity is an increase in teacher skills in using learning media. Generally, the participants of training attended the activity enthusiastically and this training's benefit could be seen from 95\% participants saying that the material of the training was relevant to the participants' needs.

\section{PENDAHULUAN}

Penggunaan media pembelajaran yang bervariasi memerlukan kompetensi guru. Guru yang kompeten ia lah tuntutan profesionalisme. Hal ini sejalan dengan kebija kan pemerintah dalam UU No. 14 Tahun 2005 Pasa17 yang menyatakan bahwa pemberdayaan profesi guru diselengga rakan melaluipengembangan diriyang dilakukan secara demokratis, berkeadilan, tidak

ISSN 2460-9447 (print), ISSN 2541-5883 (online)

${ }^{*}$ Corresponding author: Wiedy Murtini

Pendidikan Administrasi Perkantoran, Fakultas Keguruan dan Ilmu Pendidikan, Universitas Sebelas Maret, Jalan Insinyur Sutami No.36 A Kentingan, Jebres,. Jebres, Surakarta 57126, Jawa Tengah, Indonesia

Email: idik_53@yahoo.co.id 
diskriminatif, dan berkelanjutan dengan menjunjung tinggi hak asasi manusia, nilai keagamaan, nilai kultural, kemajemukan bangsa, dan kode etik profesi. Yusutria (2017) menyebutkan bahwa kriteria profesionalisme guru meliputi kemampuan untuk menguasai bahan, mengelola PBM, mengelola kelas, mengelola media atau sumber, menguasai landasan kependidikan, mengenal interaksi belajar mengajar, menilai prestasi siswa, mengenal fungsi dan program pela yanan BP, serta mengenal a dministrasi sekolah.

Di Indonesia, pengembangan kompetensi guru masih belum berjalan secara optimal sehingga kompetensi yang dimilikioleh mayoritas guru masih di bawah standar. Kenyataan ini kurang baik karena kualitas pendidikan tergantung pada kualitas guru, yaitu kompetensi profesional (Sharma \& Pandher, 2018). Salah satu jenjang pendidikan yang memiliki nilaiuji kompetensi guru (UKG) rendah adalah jenjang SMK. Penelitian yang dilakukan oleh Murtini et al. (2017) menunjukkan bahwa penyebab rendahnya kompetensi guru adalah minimnya pelatihan yang diikuti dan ketidaksesuaian antara materi pelatihan dengan kebutuhan guru sehingga mayoritas guru kurang mendapatkan fasilitas guna mengembangkan kompetensinya. Tindak lanjut dari studi pendahuluan tersebut ialah pengembangan model pelatihan berda sarkan kebutuhan serta kesesuaian dengan calon peserta pelatihan. Model pelatihan yang telah dikembangkan ia lah model Need-Based Training-Plus (NBT-Plus).

Pembelajaran tidak hanya berfokuspada saat guru menyampaikan materi, tetapi juga tentang bagaimana peserta didik da pat memahami materi. Yamin (2013) mengatakan bahwa pembelajaran a dalah kemampuan da lam mengelola komponen pembelajaran sehingga menghasilkan nilai tambah yang sesuai dengan noma yang berlaku. Saat ini pembelajaran ditekankan pada student centered learning, ya itu model pembelajaran yang ditunjang dengan media pembelajaran berbasis teknologi. Dukungan teknologi dalam pembelajaran bertujuan untuk menghilangkan pandangan siswa tentang belajar sebagai kegia tan yang membosankan.

Anitah (2009) mengatakan bahwa media pembelajaran meliputi segala sumber yang dipertukan untuk berkomunikasi dalam pembelajaran sehingga bentuknya bisa berupa perangkat keras dan perangkat lunak. Media pembelajaran yang dirancang dengan ba ik, diproduksi secara terampil, da n digunakan secara efektif akan berpengaruh besar pada kegiatan pembelajaran (Naz \& Akbar, 2008).

Salah satu media pembelajaran yang ditawarkan adalah Lectora Inspire. Lectora Inspire merupakan salah satu software penghasilmedia pembelajaran yang interaktif. Media Lectora Inspire dipilih untuk mengatasi permasalahan karena fitur-fitur yang disediakan sangat sederhana sehingga memudahkan pengguna pemula ketika membuat multimedia (video dan audio) pembelajaran. Hasil penelitian Akbarini et al. (2018) menunjukkan bahwa terja di peningkatan hasil belajar peserta didik yang diberi treatment penggunaan media pembelajaran Lectora Inspire. Hasil belajar kelas eksperimen menunjukkan nilai ra ta-rata post-test 84,53. Adapun hasil belajar untuk kelas kontrol menunjukkan nilai post-test rata-rata 71,73. Da la m pengabdian ini, pelatihan a kan dikombinasikan dengan modelNBT-Plus a gar pemonitoran dapat lebih efektif. Pelatihan media pembelajaran Lectora Inspire dengan model NBT-Plus dilaksanakan di Sekolah Menengah Kejuruan Administrasi Perkantoran, Sura karta. Pelatihan ini diharapkan dapat menjadi salah satu cara untuk memenuhi kebutuhan guru, yaitu meningkatkan kompetensi.

\section{METODE}

Penyampaian materi dalam kegiatan pengabdian kepada masyarakat ini dilakukan dengan metode ceramah. Rangkaian aktivitas kegia tan terdiri atas tahap persiapan, tahap pelatihan, dan tahap pemonitoran. Tahap persia pan dia wali dengan kegiatan koordinasi dengan ketua MGMP Administrasi Perkantoran Kota Sura karta. Pa da tahap pelatihan dilaksanakan pelatihan mengenai media pembelajaran Lectora Inspire. Peserta merupakan guru Administrasi Perkantoran se-Kota Surakarta. Pada tahap terakhir, yaitu pemonitoran dilakukan pendampingan dengan model NBT-Plus. Pemonitoran dilakukan selama beberapa waktu dan dipantau melalui WhatsApp group.

\section{HASILDAN PEMBAHASAN}

Kegiatan pengabdian kepada masyarakat ini diawali dengan koordinasi dengan mitra. Hal ini bertujuan untukmenambah keterampilan guru dalampenggunaan media pembelajaran. Setelah koordinasi, kegiatan selanjutnya adalah pelatihan dan pemonitoran. Kegiatan tersebut dilaksanakan agar guru mampu menggunakan media pembelajaran Lectora Inspire secara berkelanjutan. Hasil kegiatan ini dapat dijela skan sebagaiberikut.

\subsection{Koordinasi dengan mitra}

Sasaran kegiatan pengabdian ini adalah guru administrasi perkantoran di Kota Surakarta yang tergabung dalam Musyawarah Guru Mata Pelajaran (MGMP). Kegiatan yang dilakukan mengacu pada penelitian sebelumnya, yaitu mengenai pemetaan kompetensi guru a dministrasi perkantoran berbasis uji kompetensi guru dan alternatif pemecahannya. Berda sarkan a nalisis a wal diketahui bahwa guru SMK Administrasi Perkantoran membutuhkan pelatihan media pembelajaran berbasis IT (Murtini et al., 2017). 
Pelatihan yang akan dilakukan merupakan hal yang benar-benar diinginkan dan dibutuhkan oleh para guru. Sebelum pelaksanaan pelatihan, pengabdi berkoordinasi dengan ketua MGMP Administrasi Perkantoran Kota Surakarta. Dari hasil koordinasi diketahui bahwa media pembelajaran dibutuhkan pada mata pelajaran yang banyak teori. Hal ini dilakukan agar peserta didik tidakjenuh mengikuti pembelajaran.

Media pembelajaran Lectora Inspire cocok diterapkan pada mata pelajaran yang banyak teori karena memungkinkan guru untuk menyusun materi pela jaran secara runtut da ri kompetensi da sar hingga evaluasi. Pa da koordinasi ini disepakati bahwa peserta pela tihan a dalah guru pengampu mata pelajaran humas dan keprotokolan se-Kota Surakarta yang berjumlah dua puluh orang.

\subsection{Pelatihan media pembelajaran Lectora Inspire}

Pada pelatihan media pembelajaran Lectora Inspire ini, ketua pengabdi memberikan pemahaman mengenai pentingnya penggunaan media pembelajaran digital untuk peserta didik saat ini. Jenis media pembelajaran berkembang seiring kemajuan teknologi, mulai dari media sederhana sampai media digital. Meskipun telah banyak dikembangkan, tidak banyak guru yang menggunakan media pembelajaran interaktif (Faruk, 2014), padahal media pembelajaran menjadi sara na penting bagi guru karena merupakan salah satu komponen dalam pembelajaran.

Guru-guru membutuhkan pelatihan semacam ini untuk memperbanyak gudang ilmu pengetahuan mengenai media pembelajaran yang aktif dan inovatif di dalam kelas. Setelah pelaksanaan pelatihan, peserta tetap dipantau agar membuat media pembelajaran sendiri. Mereka dapat menanyakan hal-hal yang belum dipahami melalui WhatsApp group yang dibuat oleh tim pengabdi. Peserta pelatihan tampak antusias mengikuti pelatihan ini. Hal tersebut terlihat dari beberapa pertanyaan yang disampaikan oleh guru berikut ini.

a. Bagaimana cara mengaplikasikan dalam pembelajaran praktik?

b. Bagaimana cara melakukan evaluasi?

c. Bagaimana cara menghubungkan ke PowerPoint yang sudah ada?

d. Bagaimana cara menyimpan hasil?

e. Ba ga imana cara mengedit ulang?

f. Bagaimana cara mengoperasikannya?

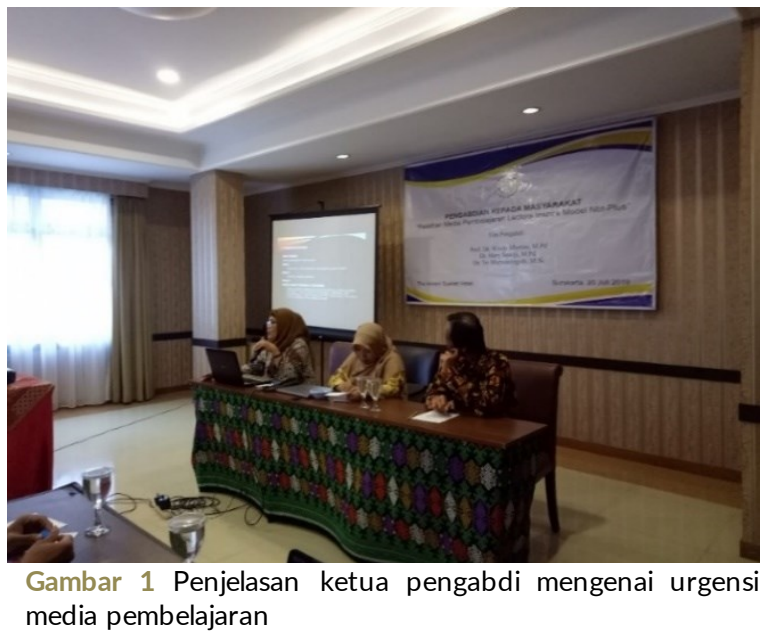

Dalam pembelajaran diperlukan variasi penyampaian bahan ajar. Pendidik yang kreatif selalu memberikan media yang interaktif sehingga membuat peserta didik tertarik untuk belajar. Media adalah salah satu perantara yang menjadi alat bantu dalam menyampaikan materi. Media pembelajaran semakin bermanfaat apabila disesuaikan dengan pokok bahasan materi ajar. Dalam proses pembelajaran, terdapat beberapa prinsip dalam memilih media. Prinsip-prinsip tersebut ialah pemilihan media pembelajaran, objektivitas media pembelajaran, memahamikelebihan setiap media pembelajaran, memahami karakter setiap media pembelajaran, memperhatikan berbagai syarat dalam memilih media pembelajaran, dan memperhatikan faktor yang memengaruhi penggunaan media pembelajaran (Wati, 2016). Media pembelajaran digunakan untuk memfasilitasi komunikasi dalam pembelajaran (Smaldino et al., 2005).

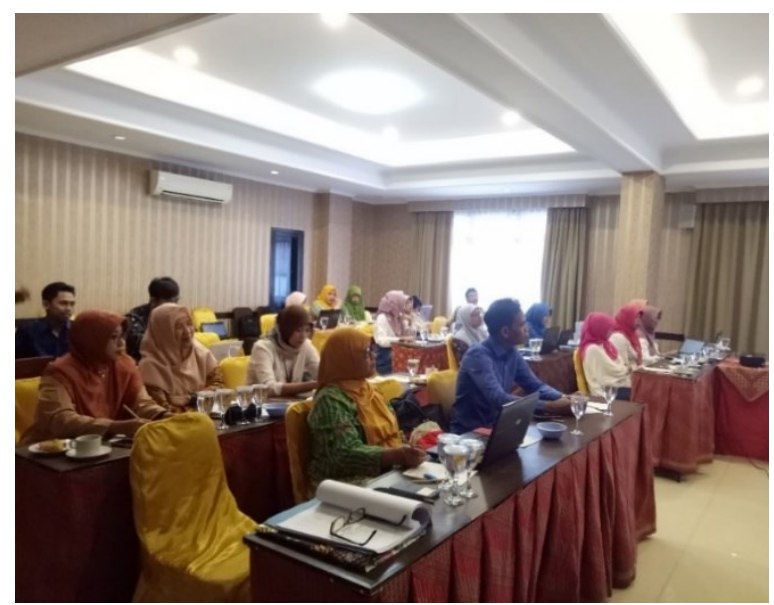

Gambar 2 Peserta pelatihan media pembelajaran Lectora Inspire

Lectora Inspire merupakan salah satu media pembelajaran yang dapat dikembangkan saat ini. Mas'ud (2014) mengatakan bahwa Lectora memperoleh penghargaan dalam bidang produk $e$ learning inovatif, authoring tool, tool presentasi terbaik, dan teknologi e-learning terbaik pada 2011. 
Kelebihan Lectora Inspire, antara lain, fitur-fitur yang disediakan dapat memudahkan pengguna pemula ketika membuat multimedia pembelajaran, template yang disediakan cukup lengkap, tersedia media library yang sangat membantu pengguna, dan sangat memungkinkan pengguna untuk mengonversi presentasi Microsoft PowerPoint ke konten e-learning. Materi yang disampaikan dalam pelatihan meliputi penyusunan flowchart dan story board, penggunaan animasi, pembuatan kuis, dan pembuatan media pembelajaran secara keseluruhan.

Dalam pelatihan media pembelajaran Lectora Inspire ini, peserta diberi keterampilan menyusun materi ke dalam media pembelajaran yang interaktif. Untuk menyusun materi pada media ini, hal-hal yang

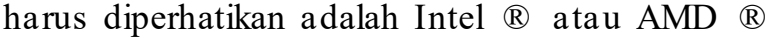
prosesor, $500 \mathrm{MB}$ RAM, ruang hard disk 1,1 GB kosong untuk aplikasi, dan Microsoft.NET Framework 4.0 SP1. Lectora Inspire yang digunakan adalah Lectora Inspire versi 17. Sebelum membuat media pembelajaran Lectora Inspire, guru harus membuat flowchart dan story board. Oleh karena itu, pengabdi menyampaikan agar ketua MGMP Administrasi Perkantoran Kota Surakarta bersama guru menyusun flowchart dan story board terlebih dahulu sebelum pelatihan berlangsung. Berikut ini contoh flowchart untuk membuat media pembelajaran Lectora Inspire.

Cover

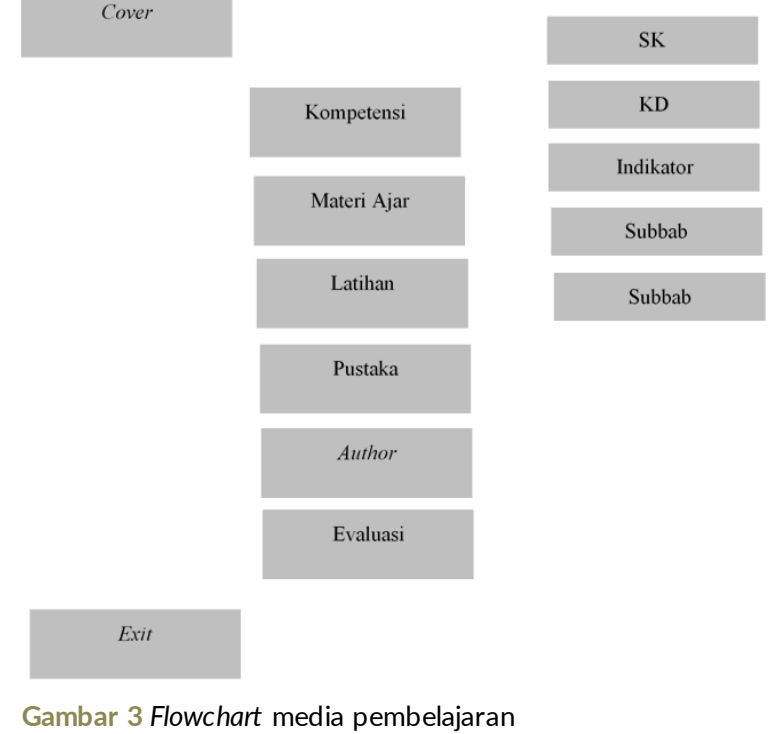

Flowchart adalah bagan dengan simbol-simbol tertentu yang menggambarkan urutan proses secara mendetail da n hubungan antara suatu proses (instruksi) dengan proses lainnya dalam suatu program. Flowchart da lam media pembelajaran Lectora Inspire berfungsi untuk menggambarkan rangkaian proses materi dari awal sampai akhir yang akan disusun da lam media pembelajaran. Flowchart ini akan memudahkan pendidik dalam mendesain media pembelajaran. Setelah flowchart disusun, la ngkah selanjutnya adalah membuat story board yang berfungsi untuk mendesain hal-hal yang akan ditampilkan pada media pembelajaran.

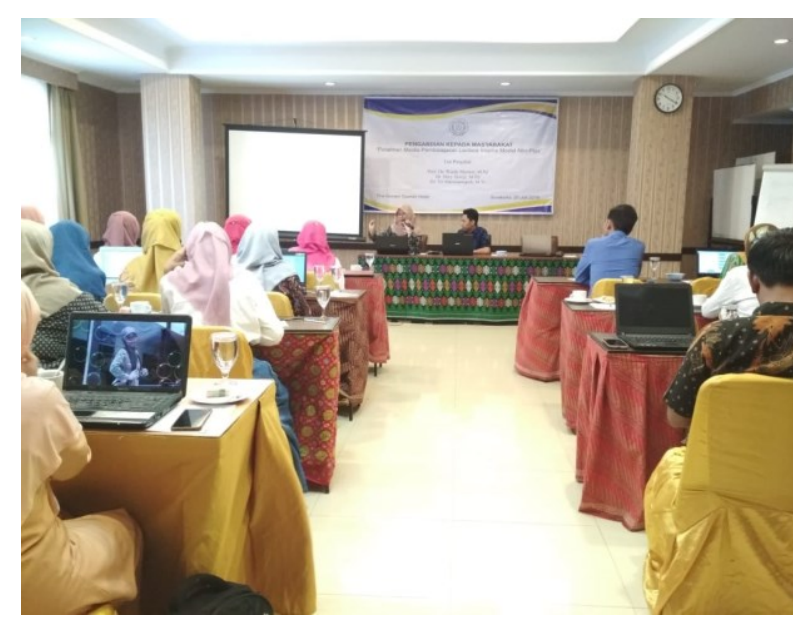

Gambar 4 Penjelasan mengenai media pembelajaran

Penjelasan mengenai media pembelajan Lectora Inspire dilanjutkan den gan penyampaian materi dasardasar Lectora yang meliputi menu-menu pada program Lectora, pemanfaatan chapter, section, page, insert berbagai fa silitas dalam Lectora (insert image, insert audio), animasi, pemanfaatan fasilitas pembuatan soal/kuis, dan publish. Menu pada Lectora terdiri atas menu file, home, design, insert, test \& survey, tools, view, dan properties yang cara kerjanya mirip dengan program Microsoft Office. Penjelasan selanjutnya berkaitan dengan langkah kerja Lectora Inspire. Hal hal yang dijelaskan kepada peserta pelatihan meliputi cara memasukkan objek gambar pada halaman kerja, cara membuat soal/materi uji, dan cara memublikasikan media. Kegia tan dirangkum dalam pelatihan sa tu hari penuh. Setiap peserta diberi modul pelatihan yang berisi langkah-langkah kerja. Peserta pelatihan tampak antusias mengikuti setiap penjelasan dari instruktur. Melalui pelatihan ini, keterampilan guru dalam mengembangkan media pembelajaran diharapkan semakin bertambah.

\subsection{Pendampingan dengan model NBT-Plus}

Setelah pelaksanaan pelatihan media pembelajaran Lectora Inspire, pengabdi melakukan pendampingan kepada peserta pelatihan. Pendampingan dilakukan secara informal melalui WhatsApp group. Peserta pelatihan dapat bertanya kapan saja tentang berbagai halyang berkaitan dengan materiyang belum dipahami. Peserta aktif bertanya dan mengirimkan tugas yang berkaitan dengan media pembelajaran. Kegiatan ini dinilai positif dan bermanfaat bagi peserta. Pendampingan peserta juga berjalan lancar. 


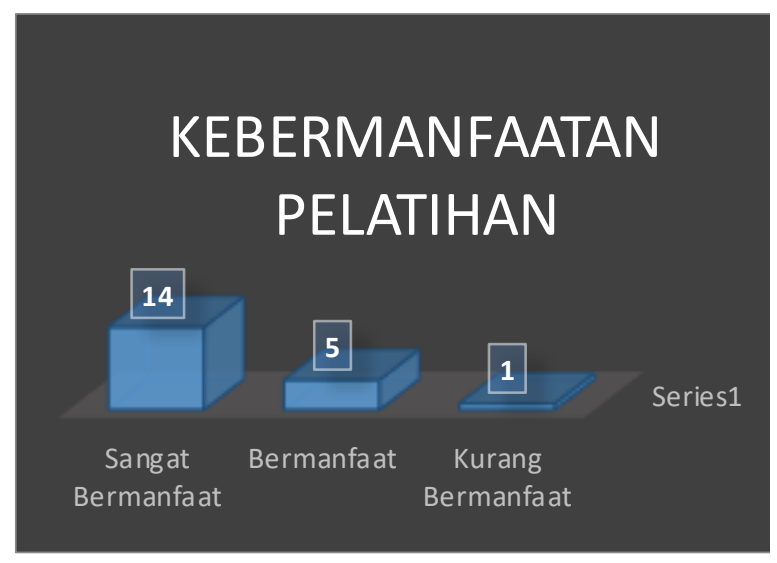

Gambar 5 Kebermanfaatan pelatihan

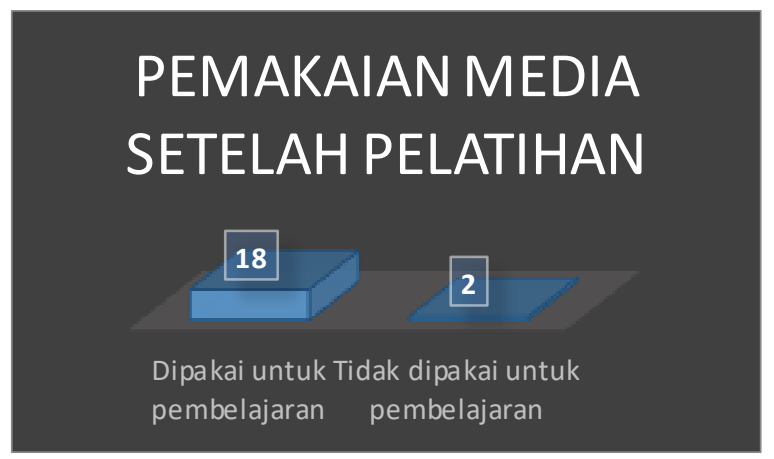

Gambar 6 Penerapan media pembelajaran setelah pelatihan

\section{KESIMPULAN}

Secara umum seluruh peserta memberikan respons positif terhadap kegiatan pelatihan ini. Kebermanfaatan pela tihan initerlihat dari persentase peserta, yaitu $95 \%$ yang berpendapat bahwa materi pelatihan ini relevan dengan kebutuhan mereka. Sela in itu, keberhasilan pendampingan setelah pelatihan dengan model NBTPlus juga terlihat dari persentase peserta, yaitu $90 \%$ yang aktif bertanya melalui WhatsApp group ketika memiliki kesulitan, mampu mengerjakan media pembelajaran Lectora Inspire secara individu, dan mampu menerapkan media ini di sekolah. Dari hasil yang telah diperoleh, media ini diharapkan dapat diaplikasikan pada mata pelajaran-mata pelajaran yang lain sehingga melatih keterampilan guru dan memberikan varia si media kepada siswa.

\section{UCAPANTERIMAKASIH}

Uca pan terimakasih kepada LPPM Universitas Sebelas Maret Surakarta, MGMP Administrasi Perkantoran, dan seluruh pihak yang telah berkontribusi dalam kegiatan pelatihan ini sehingga kegiatan dapat terlaksana dengan baik.

\section{DAFTAR PUSTAKA}

Akbarini, N.R., Murtini, W., \& Rahmanto, A.N. (2018). The Effect Of Lectora Inspire-Based Interactive Learning Media In Vocational High School. JurnalPendidikan Vokasi, 8(1), 78—87.
Anitah, S. (2009). Media Pembelajaran. Surakarta: FKIP UNS.

Faruk, Alfensi. (2014). Development of Interactive Learning Media Based Lectora Inspire in Discrete Method Course. Proceeding of International Conference On Research, Implementation, And Education If Mathematics And Science UNY.

Mas'ud, M. (2014). Tutorial 1 Membuat Multimedia Pembelajaran dengan Lectora Inspire. Yogya karta: Pustaka Shonif.

Murtini, W., Rapih, S., \& Sa wiji, H. (2017). Pemetaan Kompetensi Guru Administrasi Perkantoran Berbasis Uji Kompetensi Guru dan Alternatif Pemecahannya di Provinsi Jawa Tengah. Laporan Hasil Penelitian. Fakultas Keguruandan Ilmu Pendidikan, Universitas Sebelas Maret, Surakarta.

Naz, A.A \& Akbar, R.A. (2008). Use of Media for Effective Instruction its Importance: Some Consideration. Journal of Elementary Education, 18(1-2), 35-40.

Sharma, P.\& Pandher, J.S. 2018. Quality of teachers in technicalhigher education institutionsin India. Higher Education, Skills and Work-Based Learning, 8(4), 511-526.

Sma ldino S.E., Russell J.D, Heinich, R., \& Molenda M. (2005). Instructional Technology and Media for Learning (8ed.). New Jersey: Merrill Prentice Hall.

UU No. 14 Tahun 2005 tentang Guru dan Dosen.

Wati, E.R. (2016). Ragam Media Pembelajaran. Jakarta: Kata Pena.

Yamin, M. (2013). Paradigma Baru Pembelajaran. Jakarta: Referensi.

Yusutria. (2017). Profesionalisme Guru dalam Meningkatkan Kualitas Sumber Daya Manusia. JurnalCurricula, 2(1), 38- 46. 